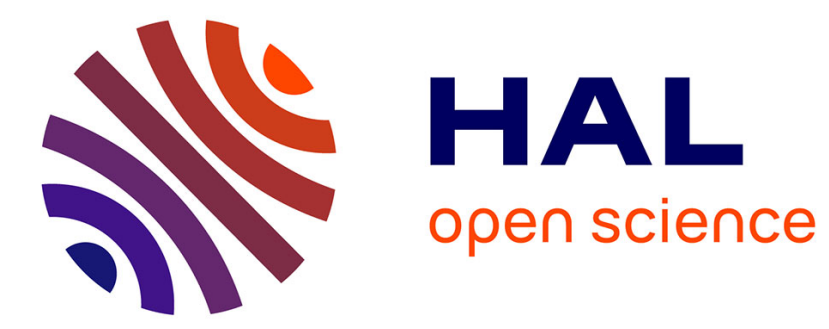

\title{
SOLUBILITY LIMIT OF DOPANTS IN SILICON IRRADIATED BY RUBY LASER
}

E. Fogarassy, R. Stuck, J. Grob, A. Grob, P. Siffert

\section{To cite this version:}

E. Fogarassy, R. Stuck, J. Grob, A. Grob, P. Siffert. SOLUBILITY LIMIT OF DOPANTS IN SILICON IRRADIATED BY RUBY LASER. Journal de Physique Colloques, 1980, 41 (C4), pp.C441-C4-45. 10.1051/jphyscol:1980407 . jpa-00219922

\section{HAL Id: jpa-00219922 https://hal.science/jpa-00219922}

Submitted on 1 Jan 1980

HAL is a multi-disciplinary open access archive for the deposit and dissemination of scientific research documents, whether they are published or not. The documents may come from teaching and research institutions in France or abroad, or from public or private research centers.
L'archive ouverte pluridisciplinaire HAL, est destinée au dépôt et à la diffusion de documents scientifiques de niveau recherche, publiés ou non, émanant des établissements d'enseignement et de recherche français ou étrangers, des laboratoires publics ou privés. 


\section{SOLUBILITY LIMIT OF DOPANTS IN SILICON IRRADIATED BY RUBY LASER}

Fogarassy, E.,Stuck, R., Grob, J.J., Grob, A. and Siffert, P.

Centre de Recherches Nucléaires, Groupe de Physique et Applications des Semiconducteurs, 67037 strasbourg-Cedex, France.

Abstract.- The solubility of several dopants ( $\mathrm{Sb}, \mathrm{Ga}, \mathrm{Bi}, \mathrm{In}$ ) in laser treated silicon has been investigated. The dojants were introduced by vacuum devosition Followed by a ruby laser irradiation. Their solubility was determined by Rutherford backscattering spectrometry measurements in channeling and random conditions. In all cases a solubility limit $C_{m}$ higher than the equilibrium solubility was found and a simple correlation with the equilibrium distribution coefficient $k_{\text {, }}$ could be established :

$$
c_{m \ell}=8.6 \times 10^{21} \mathrm{k}_{0}^{0.51} \mathrm{~cm}^{-3}+
$$

Introduction.- - It is now well established that the solubility of a dopant in a semiconductor can be significantly increased by irradiation with a high energy laser or electron beam. In silicon, for example, this effect has been reported for antimony $/ 1,2 /$, gallium /3/, platinum $/ 4 /$, arsenic $/ 5 /$, and in some cases the increase can be of several orders of magnitude. It appeared interesting to see if there is a solubility 1imit of the dopant after such a treatment. Therefore, we prepared heavily doped samples of silicon by vacuum deposition of the dopant followed by ruby laser annealing $/ 6,7 /$. The concentration of dopant introduced in substitutional site and thus the solubility were measured using Rutherford Backscattering spectrometry (RBS). Therefore, our experiments were restricted to shallow dopants heavier than silicon; $\mathrm{Sb}, \mathrm{Ga}, \mathrm{Bi}$, In. For all elements a solubility limit $C_{m l}$ independent on the laser energy was found. The values obtained were compared to the maximum solubilities found by other authors using different doping methods and laser treatments in order to see if the solubility limit found is really independent of these parameters. Finally they have been plotted against several parameters. Iike for the equilibrium solubility limit a simple correlation with the equilibrium distribution

* Work performed under cosies contract. coefficient was found.

1. Experimental conditions.-1.1. Samples.Samples used in this work were $300 \mu \mathrm{m}$ thick <lll> oriented slices of silicon cut from a boron or phosphorus doped Czochralski crystal ( $1.5-3 \Omega . \mathrm{cm}$ resistivity). The samples were chemically nolished with a white etch. Before deposition of the dopant they were rinsed in $\mathrm{H} F$ to remove the surface oxyde.

The evaporation chamber was pumped down to a pressure below $1: 0 \times 10-5$ torr. The dopant was evaporated by Joule effect. The film thickness was monitored by a quartz and the rate of deposition was maintained below $2 \mathrm{~A} / \mathrm{s}$ in order to avoid pressure rise and sample heating. The deposited thickness as measured by the monitor ranged between 20 and $200 \AA$. For the thickest samples these values were confirmed by electromechanical measurements performed with a Talystep apparatus. The amount of dopant deposited was measured in all cases by RBS and the values obtained were generally in good agreement with the indications of the monitor. 1.2 Laser treatment.- The dopant covered specimens were irradiated using the amplified monomode output of a pulsed ruby laser with energy densities in the range 1.1 to 2 $\mathrm{J} / \mathrm{cm}^{2}$. The pulse duration time was equal to $20 \mathrm{~ns}$. The laser spot was nearly uniform over its diameter $(\sim \mathrm{lcm})$ and usually one single pulse was used. After irradiation the specimens were etched with appropriate 
mixtures in order to remove the dopant which did not diffuse into the crystal.

1.3 Determination of dopant concentration.The concentration profiles of total and interstitial dopant was determined by RBS in random and channeling conditions /8/. A $2 \mathrm{MeV}{ }^{4} \mathrm{He}^{+}$ion beam $(\varnothing \simeq 2 \mathrm{~mm})$ was used and the energy of the backscattered particles was measured with a cooled surface barrier. This arrangement allowed an equivalent depth resolution of $200 \AA$ for $\mathrm{Si}$. Some measurements were also made by secondary Ion liass Spectrometry (SIMIS) which gave essentially the same profiles as RBS.

2. Results.- Figure 1 shows typical spectra obtained for a deposition of $40 \AA$ of antimony and one irradiation with a $2 \mathrm{~J} / \mathrm{cm}^{2}$ Dulse.

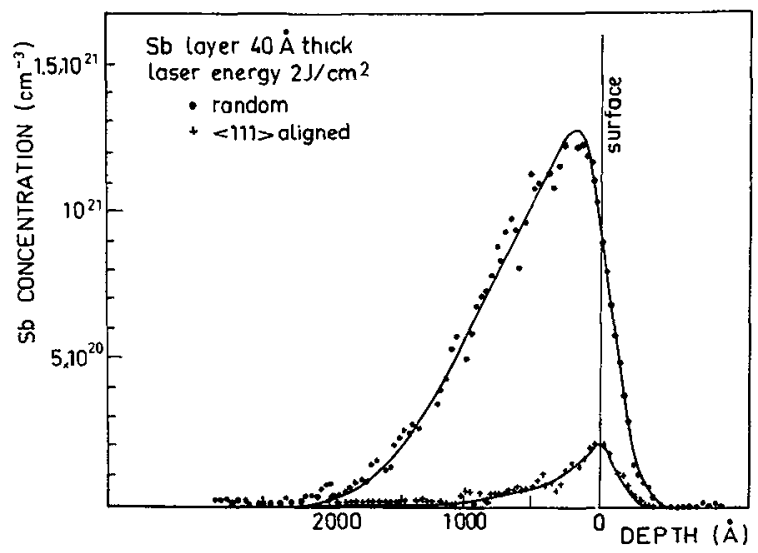

Fig.1.- RBS spectra in channeling and random conditions of a Sb doped sample.

Since the substitutional fraction is nearly the same along all axes /7/ we can estimate the solubility from the differences between the RBS Spectra under random and channeling conditions.

On figure 2 we have reported the maximum concentration of dopant as well as the maximum solubility measured for various laser energies and deposited thickness of antimony. It appears clearly that the solubility reaches a limit in all cases which is nearly independent on the laser energy and on the deposited thickness. The mean value Eound is $1.03 \times 10^{21} \mathrm{~cm}^{3}$. This solubility is much higher than the known eciuilibrium soluDility limit whici is $6 \times 10^{19} \mathrm{~cm}^{-3} / 9 /$.

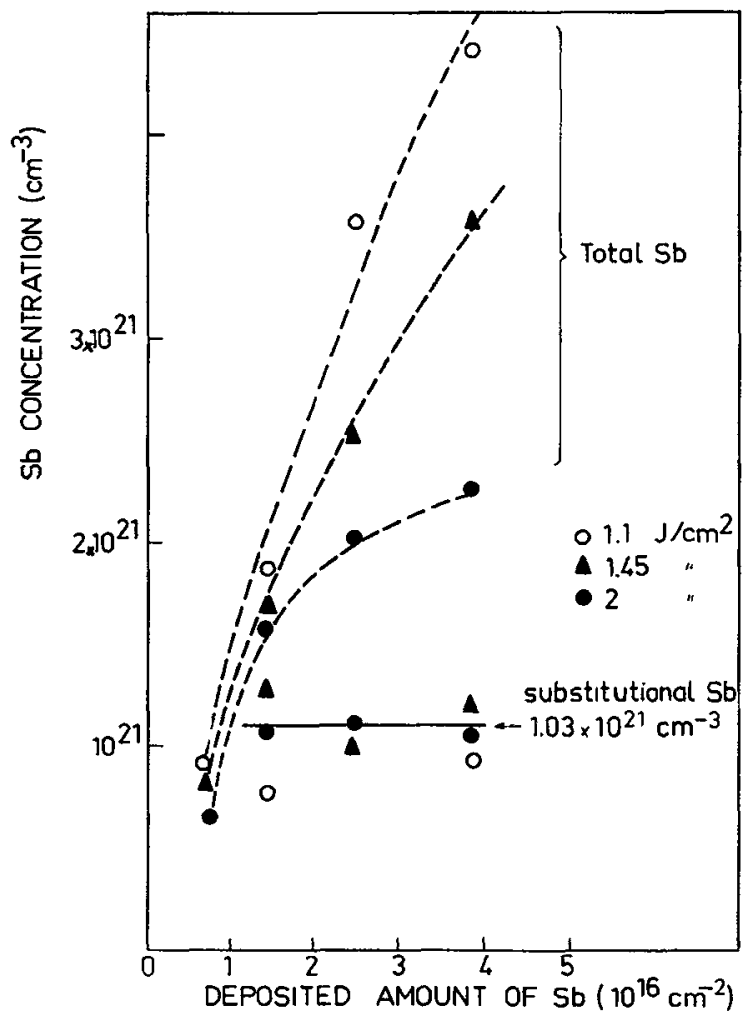

Fig.2.- Variation of the solubility of antimony as a function of the deposited amount of $\mathrm{Sb}$.

Similar experiments were performed with other dopants. Table I summarizes the results obtained as well as the equilibrium limit at $\mathrm{T}=1200^{\circ} \mathrm{C}$.

\section{TABLE I}

\begin{tabular}{|l|c|c|}
\hline & Therma1 equilibrium & Laser treatment \\
\cline { 2 - 3 } & $6 \times 10^{19} \mathrm{~cm}^{-3}$ & $1 \times 10^{21} \mathrm{~cm}^{-3}$ \\
$\mathrm{Ga}$ & $5 \times 10^{19} "$ & $9 \times 10^{20} "$ \\
$\mathrm{Bi}$ & $8 \times 10^{17} "$ & $3 \times 10^{20} "$ \\
$\mathrm{In}$ & $6 \times 10^{17}$ & $1.5 \times 10^{20 "}$ \\
\hline
\end{tabular}

Since these solubility limits have been obtained for a particular doping process and a particular laser treatment it appeared interesting to see if the same value is found for other doping process (implantation) and for other laser irradiations (YAG, $\mathrm{CO}_{2}$ lasers) or even for e-beam irradiation.

Studies made on implanted samples gave essentially the same results. Table II shorts a comparison of the solubility limits found here with the maximum solubility reported by thite /5/ on ion implanted $S i$ annealed with a ruby laser. 
Excepted for $\mathrm{Ga}$, the agreement between the results obtained by the two methods is good. This indicates that the solubility limit is not dependent on the way the dopant is introduced.

TABLEAU II

\begin{tabular}{|l|r|r|}
\hline & Our experiments & White results /5/ \\
\cline { 2 - 2 } & & $6 \times 10^{21} \mathrm{~cm}^{-3}$ \\
$\mathrm{Sb}$ & $1 \times 10^{21} \mathrm{~cm}^{-3}$ & $1.3 \times 10^{21 " ~}$ \\
$\mathrm{Ga}$ & $9 \times 10^{20} "$ & $4.5 \times 10^{20} "$ \\
$\mathrm{Bi}$ & $3 \times 10^{20} "$ & $4 \times 10^{20} "$ \\
$\mathrm{In}$ & $1.5 \times 10^{20} "$ & $1 \times 10^{20} "$ \\
\hline
\end{tabular}

The question to know if the solubility limit depends on the laser treatment is more difficult to answer, since no solubility limit measurements have been done with other lasers or $e^{-}$beams.

However, the same high substitutionality has been reported for ruby laser and $c$ i electron beam irradiation of As implanted si/10/. Furthermore, similar results have been reported for $\mathrm{CW}$ Argon laser and $\mathrm{CWN}^{-}$ beam $/ 11 /$. Thus, although this has to be carefully verified, it appears that the same solubility can be expected for all laser and electron beams used.
An attempt was made to plot these values of the solubility Iimit against otiner para.. meters. One of the chosen parameters was the equilibrium distribution coefíicient since Fischler $/ 12 /$ has observed that in equilibrium conditions, both for silicon and germanium and for most impurities the experimental maximum molar solubility $x_{m}$ is about one tenth of the distribution coefficient $k_{0}$ at the melting point. Some basis for this dependence from thermodynamical considerations has been given by statz /13/. For impurities in silicon the expected solid solubility should be

$$
c_{m}=\left(5.2 \times 10^{21}\right) \mathrm{k}_{\mathrm{o}} \mathrm{cm}^{3}
$$

on figure 3 we have potted our values of $\mathrm{C}_{\mathrm{m} \ell}$ (and also the maximum solubilities found by other authors for a laser process) against $k_{o}$. It appears that a simple correlation exists between $C_{m \ell}$ and $k_{0}$.

$$
c_{m \ell}=\left(8.6 \times 10^{21}\right) \mathrm{k}_{0}^{0.51} \mathrm{~cm}^{3} \text {. }
$$

It should be noticed that this equation holds for both group III and $V$ elements and for $k_{0}$ values ranging over about four orders of magnitude.

The solubility limits have been also

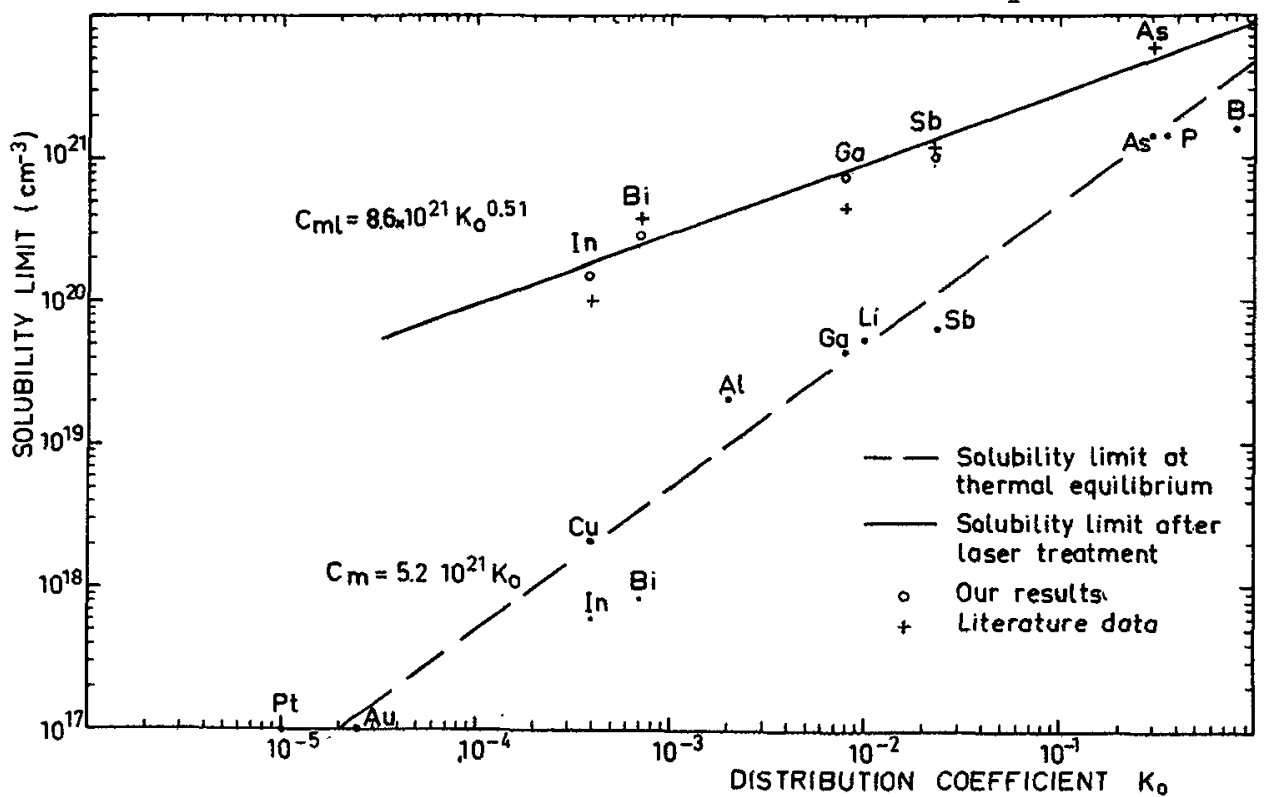

Fig.3.- Correlation of the solubility limits at thermal equilibrium and after laser treatment with equilibrium distribution coefficients. 
correlated to the tetraedral radius (Fig.4). Like for equilibrium conditions two different dependences are obtained for acceptor and donor impurities.

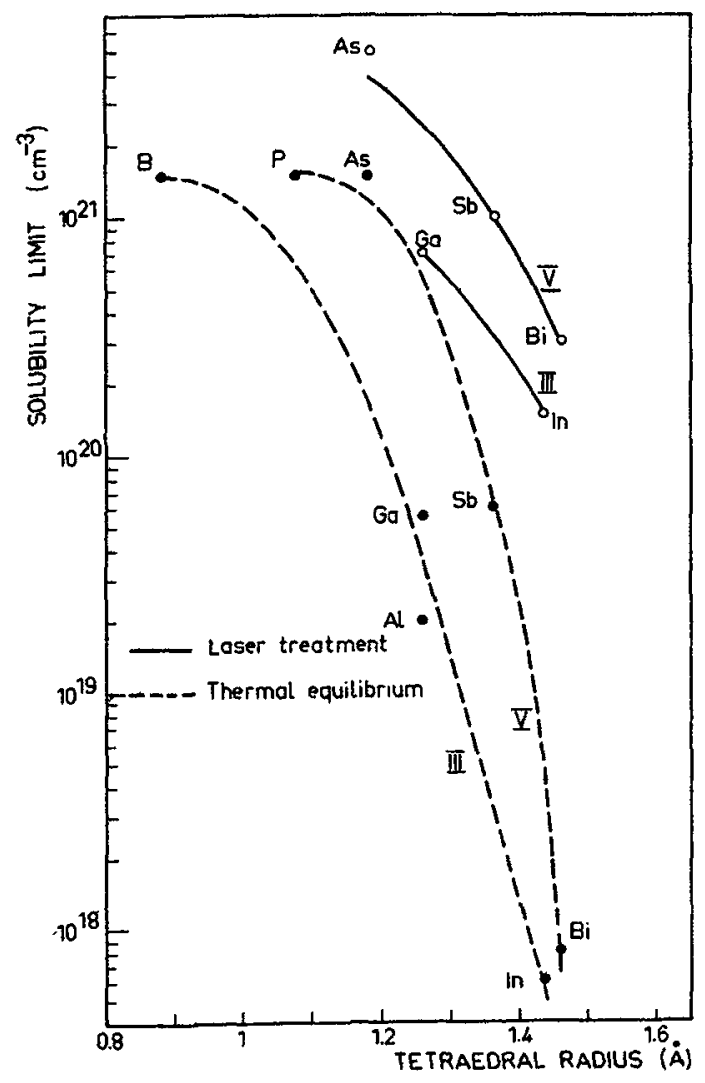

Fig.4. - Variation of the solubility limit at thermal equilibrium and after laser treatment as a function of tetraedral radius.

3. Discussion.- Although the mecanism of laser annealing is not yet finally established /I4/ we can try to interpret our results using the thermai ("melting") model $115,16 /$.

This model assumes that the energy of the incident photons is converted into heat in the lattice in a layer of depth given by the photon absorption length and in a time small compared to the duration of the pulse, that this thermal energy leads to the melting of the surface and that the recrystallization process which occurs as the material cools is liquid phase epitaxial growth. With these assumptions the fact that the solubility limit is exceeded can be interpreted by considering trapping of the dopant as suggested by Jackson and Leamy $/ 17 /$. According to these authors, the atoms of the silicon matrix can convert from liquid to solid without long distance motion, whereas the excess of dopant would have to diffuse over long distances in order to be Erozen in the rapidly moving interface. Thus the solubility of the dopant should depend on its mobility at the interface and on the recrystallization velocity. strictly speaking the results presented here should therefore be valid only for ruby lasers. Furthermore the fact that the solubility is independent on the laser energy can be explained by considering that the interface velocity is nearly independent on the laser energy in the range used here /18/. Finally the existence of a simple correlation between $\mathrm{C}_{\mathrm{ml}}$ and $\mathrm{k}_{\mathrm{o}}$ for the dopants may be due to the fact that they have nearly the same mobility at the interface. This relation does probably not hold for all impurities.

4. Conclusion.- This work demonstrates the existence of a solubility limit of dopants in ruby laser treated silicon. This limit is nearly independent of doping conditions and laser energy. A simple relationship has been found between the solubility limit and the equilibrium distribution coefficient.

It allows to predict the solubility limit of any dopant and also it may help to understand the fundamental mechanism of the interaction of laser with silicon.

\section{References}

/1/ White, C.W.Narayan, J. and Young, R.T. in Laser Solid Interactions and LaLaser Processing, Boston (1978) (AIP Conf. Proc.50) Ed. by S.D. Ferris, H.J. Leamy and J.M. Poate, P. 275 .

/2/ Revesz, P. Farkas, G.Y. and Gyulai, J. in Laser Effects on Ion implanted Semiconductors (1978) (Proc. of the Catania Conf.) Ed. by E. Rimini, P. 184 .

/3/ Bean, J.C. Leamy, H.J. Poate, J.M. and Celler, G.K. in Laser Solid Interactions and Laser Processing, Boston (1978) (AIP Conf.Proc.50) Ed. by $S$. F. Ferris, H.J. Leamy and J.M. Poate p. 487 . 
/4/ Cullis, A.G. Poate, J.M. and Celler, G.K. in Laser Solid Interactions and Laser Processing, Boston (1978) (AIP Conf. Proc.50)Ea. by S.D. Ferris, H. J.Leamy and J.P. Poate, p.311.

/5/ Thite, C.W. Private communication

/6/ Narayan, J. Young, R.T. Wood, R.F. and Christie, W.H. Appl. Phys. Lett.33 (1978) 338 .

17/ Stuck, R. Fogarassy, E. Grob, A. Grob, J.J. Muller, J.C. and Siffert, P. in Laser and Electron Beam Processing of Electronic laterials, Los Angeles (1979)

/8/ Chu, W.K. Mayer, J.M. and Nicolet, M.A. Backscattering spectrometry, (Ed.by Academic Press) 1978.

19/ Trumbore, F.A. Bell Syst. Techn. J.39 (1960) 205.

/10/Wilson, S.R. Appleton, B.R. Wite, C.T. and Narayan, $J$. in Laser Solid Interactions and Laser Processing, Boston (1978) (AIP Con.Proc.50) Ed. by S.D. Ferris, H.J. Leamy and J.ll. Poate, ?. 481.

/11/ Regolini, J.I. Sigmon, T.V. and Gibbons J.F. Appl. Phys. Lett.35 (1979) 114.

/12/ Fischler, S., J. Appl. Phys.33, (19623) 1615 .

/13/ Statz, H. J. Phys. Chem. Solids 24, (1963) 699.

/14/Van Vechten, J.A. These Proceedings

/15/ wang, J.C. Tood, R.F. and Pronko, P.P. Appl. Lett.33, 455 (1978).

116/ Baeri, P. Campisano, S.U. Foti, G. and Rimini, E. J. Appl. Phys.50, (1979) 788 .

117/ Jackson, K.A. and Leamy, H.J. in Laser laser Solid Interactions and Iaser Processing, Boston (1978) (AIP Conf. Proc. 50) Ed. by S.D. Ferris, H.J. Leamy and J.M. Poate, p. 103.

118/ Jastrebski, L., Bell A.E. and Wu, C.P., Appl. Phys. Lett. 35, (1979), 608 . 